\title{
Prevalence and correlates of sexual dysfunction among patients with mental disorders in a tertiary hospital in Southwest Nigeria
}

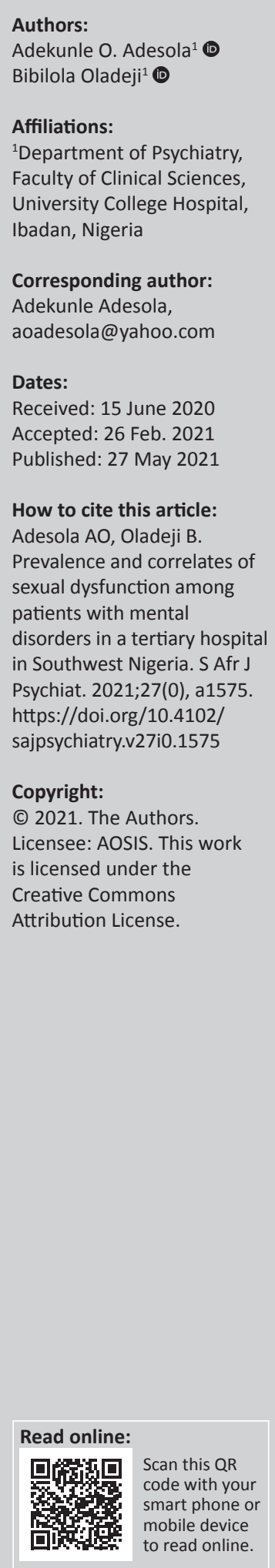

Background: Sexual dysfunction is more common among patients with mental disorders compared to the general population. Despite this high occurrence, information regarding sexual dysfunction as well as their correlates in patients receiving care for mental disorders in developing countries is still sparse.

Aim: To determine the prevalence and correlates of sexual dysfunction among patients with mental disorders receiving care in a tertiary hospital in Southwest Nigeria.

Setting: This study was performed at the psychiatric outpatient clinic at the University College Hospital, Ibadan, Southwest Nigeria.

Methods: A cross-sectional study was conducted on a convenience sample of 238 adults aged 18-60 years. Socio-demographic and clinical information was obtained from all recruited patients. Sexual dysfunction was assessed using the International Index of Erectile Function questionnaire for men and the Female Sexual Function Index questionnaire for women. Questionnaires for measuring depression, medication adherence and autonomic medication side effects were also administered. Associations between sexual dysfunction and sociodemographic and clinical factors were explored.

Results: The prevalence rates of sexual dysfunction among male and female participants were $84.7 \%$ and $95.7 \%$, respectively. In the multivariate analysis, employment status and autonomic side effects of psychotropic medications significantly predicted male sexual dysfunction, while religion and employment status were predictors of female sexual dysfunction.

Conclusion: Sexual dysfunction is very common among patients with mental disorders, with higher rates in female participants. There is a need for clinicians to consider routine screening for sexual dysfunction in psychiatric outpatients with a view of providing psychosocial interventions to improve patient's quality of life.

Keywords: prevalence; correlates; sexual dysfunctions; mental disorders; Southwest Nigeria.

\section{Introduction}

Sexual activity is regarded by the World Health Organization and the Office of Surgeon General of the United States as a basic human right and an integral part of life. ${ }^{1}$ Disturbance in sexual functioning is known to affect individuals' sense of personal satisfaction and impair healthrelated quality of life (QoL). ${ }^{2}$ Sexual dysfunction is quite common, with rates ranging between $30 \%$ and $80.8 \%$ in the general population. ${ }^{3,4,5,6,7,8}$ In a study among female students in a university in Nigeria, Nwagha et al. reported a rate of $53.3 \%{ }^{4}$

Sexual dysfunction is reportedly higher in patients with mental disorders compared to the general population, with rates ranging between $40 \%$ and $96 \% .{ }^{9}, 10,11,12,13,14,15,16,17,18,19$ Studies reveal that $40 \%-$ $90 \%$ of patients with schizophrenia have one or more forms of sexual dysfunction..$^{9,10,12}$ Among patients with depression on treatment, sexual dysfunction is present in up to $50 \%$ of the female participants and $40 \%$ of the male participants. ${ }^{13}$ In a recent study conducted in Nigeria, Olisah et al. found a prevalence rate of $64.3 \%$ among outpatients with schizophrenia, substance use disorder, recurrent depressive disorder and bipolar affective disorder receiving psychotropic medications. ${ }^{14}$

Studies on the rates of sexual dysfunction types among patients with mental disorders and those without have not consistently demonstrated a difference. While some studies report that sexual dysfunction prevalence is higher in patients with mental disorders, ${ }^{20}$ others show lower prevalence rates. ${ }^{14}$ According to a study conducted by Simiyon et al. among Indian women with 
schizophrenia, the rates of sexual desire, arousal and orgasmic disorders were reported to be $100 \%, 92.1 \%$ and $76.2 \%$, respectively. ${ }^{20}$ In contrast, Esfehani et al. reported lower rates of $49.2 \%, 43.2 \%$ and $38.6 \%$ for sexual desire, arousal and orgasmic disorders, respectively, among Iranian women in the general population. ${ }^{21}$ Most studies on the prevalence of sexual dysfunction among men focussed on erectile dysfunction and also showed an inconsistent pattern. Although Oyelade et al. reported a prevalence rate of $58.9 \%$ among men in the general population, ${ }^{22}$ Olisah et al. reported a lower prevalence of $40.2 \%,{ }^{14}$ while Mosaku et al. reported a higher prevalence of $83 \%{ }^{15}$ among male patients with mental disorders.

Factors that are associated with sexual dysfunction among patients with mental disorders include increasing age, female sex, marital status, quality of marital relationship, employment status, use of first-generation antipsychotics such as haloperidol, medication dosage, medication side effects, comorbid medical conditions and presence of psychopathology. ${ }^{11,12,14,15,20}$ Psychotropic medications and their adverse effects are important risk factors for sexual dysfunction in patients with mental disorders. In a study conducted in the United Kingdom, $45 \%$ of patients on antipsychotic medications had sexual dysfunctions compared to $17 \%$ of normal controls. ${ }^{18}$ In patients on antidepressants, sexual dysfunction ranged between $25.8 \%$ and $80.3 \% .{ }^{23}$ This impaired ability in sexual experience and performance not only adds to the suffering and disability associated with mental disorders, but also increases the likelihood of nonadherence to treatment, and contributes to diminished selfesteem and confidence and negatively affects QoL. ${ }^{13}$

The few available studies on sexual dysfunction among patients with mental disorders conducted in Nigeria have estimated prevalence rates ranging from $40.4 \%$ to $83 \%{ }^{12,14,15}$ None of these studies explored the relationship between sexual dysfunction and adherence to psychotropic medications. It is also not clear from the available studies whether there are associations between sexual dysfunction and depressive symptoms as well as autonomic side effects of psychotropic medications among patients with mental disorders in Nigeria. This study was designed to fill some of these gaps by providing information on the prevalence and correlates of sexual dysfunction in patients attending a psychiatric clinic in Nigeria. Specifically, we explored the relationship between sexual dysfunction and medication adherence, depressive symptoms and autonomic side effects of psychotropic medications.

\section{Methods}

This study followed a descriptive, cross-sectional study design. Participants were consecutive consenting patients attending the psychiatric clinic at the medical outpatient department of the University College Hospital, Ibadan over a period of 6 months from November 2016 to April 2017. The University College Hospital is a tertiary teaching hospital in Southwestern part of Nigeria.
The sample size for this study was determined using the sample size formula for cross-sectional studies. An estimated sample size of 240 was derived based on the $83 \%$ prevalence of sexual dysfunction among patients with mental disorders in a previous Nigerian study, ${ }_{1}^{15}$ adding a non-response rate of $10 \%$.

Participants were adults (aged between 18 and 60 years), with a diagnosis of a mental disorder according to the International Classification of Diseases 10th edition and currently in partial or full remission, who provided voluntary written informed consent. Those who had acute illnesses, grossly disorganised thought or behaviour and/or significant cognitive impairment were excluded from the study.

Eligible participants were either given the questionnaires to complete by themselves with the support from two trained research assistants or had the questionnaires administered to them if they were unable to read or write English or Yoruba languages fluently.

\section{Instruments}

Socio-demographic and clinical information were obtained from all recruited patients by self-report. Sexual dysfunction was assessed using the International Index of Erectile Function (IIEF) questionnaire for male participants and the Female Sexual Function Index (FSFI) questionnaire for female participants. Information on depressive symptoms, medication adherence and autonomic side effects of psychotropic medications were obtained using the Becks Depression Inventory (BDI), Morisky Medication Adherence Scale 8 (MMAS 8) and the autonomic subscale of the Udvalg for Kliniske Undersogelser Side Effects Rating Scale (UKU-SERS), respectively. The Yoruba versions of the questionnaires were derived by standard iterative procedures of translation and back-translation. Either the Yoruba or the English version was administered depending on the language the patients were more comfortable with.

\section{International Index of Erectile Function Questionnaire}

The IIEF is a brief, self-administered questionnaire used for the assessment of male sexual functioning in the past 4 weeks. It has five domains comprising 15 questions that are scored on a scale of $0-5$, with 0 indicating no sexual activity or no attempt. These domains are erectile function $(Q 1-5, Q 15)$ with a maximum score of 30, intercourse satisfaction (Q6-8) with a maximum score of 15 , orgasmic function $(Q 9,10)$ with a maximum score of 10 , sexual desire $(Q 11,12)$ with a maximum score of 10 and overall satisfaction $(Q 13,14)$ with a maximum score of 10 . Higher scores denote better sexual functioning. Based on the presence and severity of sexual dysfunction, each domain is further classified into 'no dysfunction', 'mild dysfunction', 'mild to moderate dysfunction', 'moderate dysfunction' and 'severe dysfunction'. In this study, sexual dysfunction was defined as the presence of at least a mild dysfunction in one or more domains, as reported in the previous studies. ${ }^{12,14}$ In an earlier study in Nigeria, ${ }^{15}$ a reliability coefficient (Cronbach's alpha) of 0.921 was obtained. 


\section{Female Sexual Function Index questionnaire}

The FSFI is a brief, self-administered questionnaire used for the assessment of female sexual functioning in the past 4 weeks. It has six domains comprising 19 questions that are scored on a scale of $0-5$, with 0 indicating no sexual activity or no attempt. These domains are sexual desire $(\mathrm{Q} 1,2)$, sexual arousal (Q3-6), lubrication (Q7-10), orgasm (Q11-13), satisfaction (Q14-16) and pain (Q17-19), which all have a maximum score of 6 . The overall score ranges from a minimum score of 2 to a maximum score of 36, with a higher score connoting better sexual functioning. As proposed by Wiegel et al., a cut-off point of 26.55 or less was classified as female sexual dysfunction in this study. ${ }^{24}$ The instrument has been validated and shown to be sensitive and reliable in Nigeria, with Cronbach's alpha of $0.8 .^{4}$

\section{Morisky Medication Adherence Scale 8}

The MMAS 8 is an eight-item, self-administered questionnaire used for the assessment of medication adherence among patients with different clinical conditions and has been used in some Nigerian studies. ${ }^{25,26}$ Each item measures specific medication-taking behaviour and provides a measure adherence to medications. Items 1-7 were recorded as a 'yes' or 'no' dichotomous response and the last item was recorded using a five-point Likert scale. Morisky Medication Adherence Scale 8 scores can range from 0 to 8 and score ranges are classified into three levels of adherence to facilitate use in clinical practice: high adherence, a score of 0 ; medium adherence, a score of 1-2; and low adherence, a score of $\geq 3$.

\section{The Udvalg for Kliniske Undersogelser Side Effects Rating Scale}

The UKU-SERS is a questionnaire that measures the side effects of medications in the past 3 days. It comprises 48 items that are categorised into psychic subscale (1.1-1.10), neurologic subscale (2.1-2.8), autonomic subscale (3.1-3.11) and others (4.1-4.19). The subscales are useful in assessing differential side effect profiles. The autonomic subscale of the self-rated version was used in this study to assess the presence of autonomic side effects of prescribed psychotropic medications. Each item is scored on a four-point Likert-type scale (0-3), a score of 0 indicating 'not or doubtfully present'. Scores $1-3$ indicate that a symptom is present to a mild, moderate or severe degree, respectively. The scale can be used in both clinical practice and trial. It has been adapted to suit the study population.

\section{The Beck Depression Inventory}

The BDI is a 21-item self-rated questionnaire designed to assess the intensity of depressive symptoms among individuals. Each item is scored on a Likert scale of $0-3$ in terms of increasing intensity and is summed up giving a minimum and maximum score of 0 and 63, respectively. The total scores are interpreted as 0-10 (normal), 11-16 (mild mood disturbance), 17-20 (borderline depression), 21-30 (moderate depression), 31-40 (severe depression) and $>40$ (extreme depression). The BDI has been validated among the adolescent ${ }^{27}$ and adult population ${ }^{28}$ in Nigeria and has been widely used in previous Nigerian studies. 29,30

\section{Statistical analysis}

Data were cleaned and entered into Microsoft Excel spreadsheet and statistical analysis was performed using SPSS 22.0. Categorical data were summarised into tables, while continuous data were summarised using mean and standard deviation. Pearson's chi-square test or Fisher's exact test was used to determine the association between categorical dependent variables, while independent $t$-test or analysis of variance was applied to continuous dependent variables. Pearson's correlation coefficient was used to test the association between continuous dependent and independent variables. The independent variables found to be significantly associated with sexual dysfunctions were included in logistic regression models for categorical variables and linear regression models for continuous variables. All analysis was two-tailed and the level of significance was set at $p<0.05$.

\section{Ethical considerations}

Ethical approval was obtained from the University of Ibadan/University College Hospital's Ethics committee, reference number: UI/EC/16/0144. The purpose of the study was explained to all the participants and those who were willing to participate in the study provided written informed consent. Serial numbers were allotted to the participants to anonymise the questionnaires, such that data collected could not be linked to participants. Refusal to participate in the study did not alter the quality of treatments participants received.

\section{Results}

\section{Socio-demographic and clinical characteristics of participants}

Over the study period, 238 participants were eligible for inclusion in the study, of which $144(60.5 \%)$ were male participants. The mean age of the participants was 35.71 years (standard deviation: 9.53 years). Over half of the participants had tertiary education (57.1\%) and were single (55\%), while $33.6 \%$ were unemployed and $39.1 \%$ were involved in unskilled work (such as causal factory workers, messengers, janitors and desk clerks).

Over three-quarters $(78.6 \%)$ of the participants were aged above 18 years at the onset of illness, with a mean age of 25 years. About two-thirds of the participants (61.3\%) presented for treatment within 1 year of onset of symptoms of their mental disorders and $63.4 \%$ had three or more previous episodes of mental disorders. Over half (54.2\%) had been using medications for at least 12 months. In terms of diagnosis, the most common disorder presenting to this clinic was schizophrenia (61.3\%), followed by bipolar affective disorder (16.8\%) and depressive disorder (13\%). Using the Beck's Depression Inventory, regardless of diagnosis, 34.6\% of the participants were found to have depressive symptoms, while low medication adherence was reported in $41.8 \%$ of patients (Table 1). 
TABLE 1: Socio-demographic and clinical characteristics of participants.

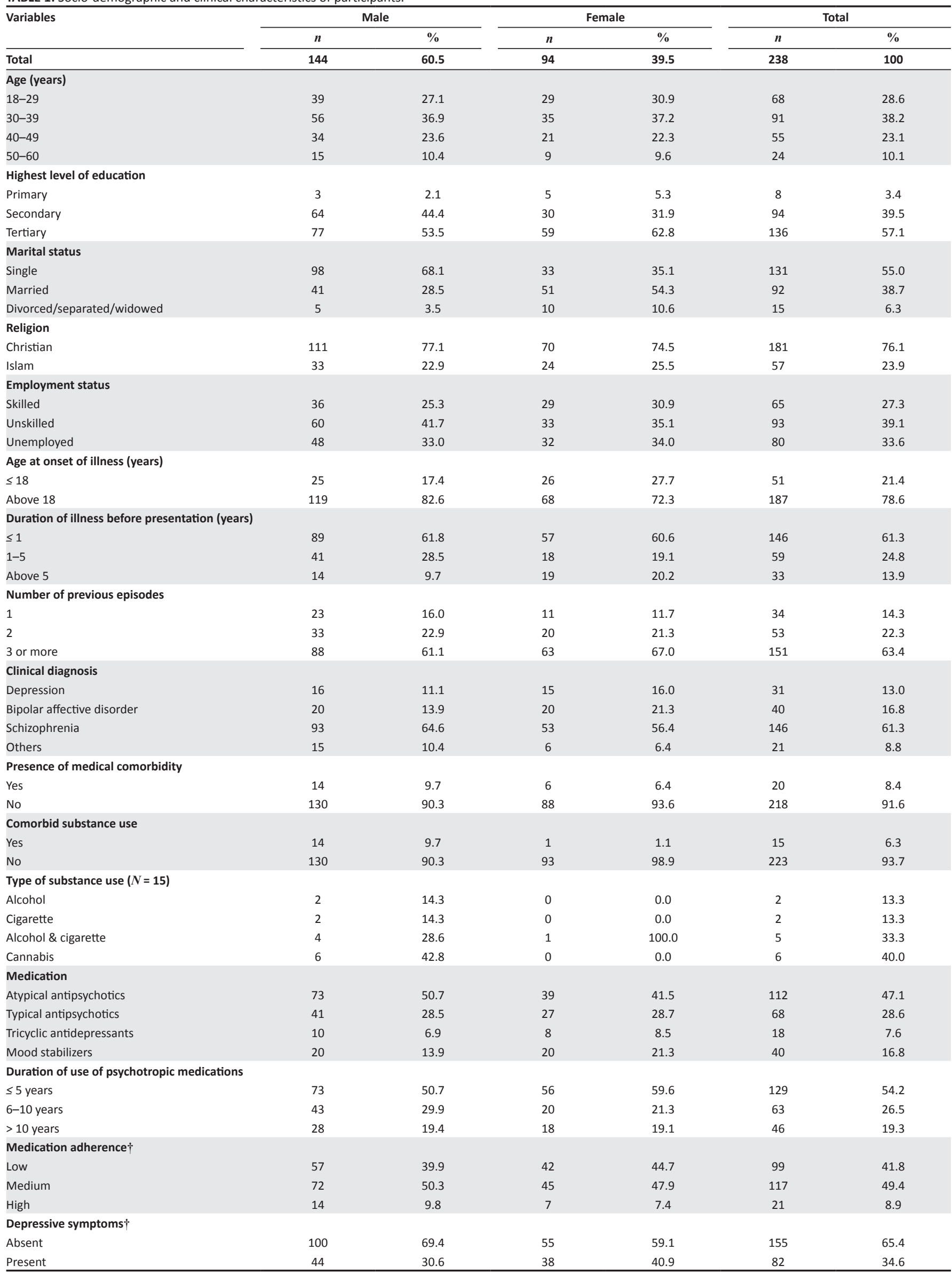

$\uparrow, n<144$ among male participants and 94 among female participants because of missing data. 


\section{Prevalence of sexual dysfunction}

The overall prevalence of any sexual dysfunction among male participants was $84.7 \%$, while this was $95.7 \%$ among female participants. The prevalence was significantly higher among female participants $\left(x^{2}=7.1, p=0.008\right)$. The most common types of sexual dysfunction were sexual desire disorder, intercourse dissatisfaction and orgasmic dysfunction for male participants.

\section{Correlates of sexual dysfunction}

The socio-demographic and clinical variables significantly associated with overall sexual dysfunction and the types of sexual dysfunction in male participants are shown in Table 2, while those for the female participants are shown in Tables 3 and 4. In male participants, overall sexual dysfunction, erectile dysfunction and sexual desire disorder were significantly associated with employment status (with highest rates among those who are unemployed), while orgasmic dysfunction was significantly associated with marital status (with highest rates among the divorced, separated and widowed).

Autonomic side effect of psychotropic medications was significantly associated with the presence of sexual dysfunction in male participants $\left(t_{\text {test }}=-2.007, p=0.047\right)$ but not in female participants.

In the female participants, overall sexual dysfunction was significantly associated with educational status $\left(x^{2}=7.5\right.$; $p=0.02)$ and religion $\left(x^{2}=5.8 ; p=0.02\right)$ (Table 3).

Disorder of sexual desire was associated with age of onset of mental disorders (with mean FSFI scores being lower among those who had age of onset before 18 years). Disorder of sexual arousal was associated with marital status (with mean FSFI scores lowest among the divorced, separated and widowed) compared to those who were married. Other socio-demographic associations for disorder of sexual arousal include religion, employment status (with mean scores lowest among those who are unemployed) and clinical diagnosis (mean scores were lowest among those with schizophrenia). Disorder of lubrication, on the other hand, was associated with educational status, marital status (mean scores lowest among the divorced, separated and widowed), religion and clinical diagnosis (with mean scores lowest among those with schizophrenia).

Orgasmic disorder was associated with educational status, marital status, religion and medication adherence (Table 4). Sexual pain disorder was associated with age (the scores being lowest in the 18-29 age group), marital status and unemployment status.

In both male and female participants, the presence or absence of depressive symptoms was not significantly associated with overall sexual dysfunction or any of the domains of sexual dysfunction.
These associations were explored further in multivariate logistic regression analysis in the male participants and linear regression models in the female participants. In the male participants, being unemployed (odds ratio [OR] $=5.4$, confidence interval $[\mathrm{CI}]=1.525,19.259)$, or being employed in unskilled work $(\mathrm{OR}=4.7, \mathrm{CI}=1.515,14.279)$ and the presence of autonomic side effects of psychotropic medications $(\mathrm{OR}=1.3, \mathrm{CI}=1.103,1.620)$ were the significant predictors of overall sexual dysfunction. For the female participants, practising Christianity was a significant predictor of sexual arousal disorder $(B=1.092, \mathrm{CI}=0.252$, 1.932) and lubrication disorder $(B=1.107, \mathrm{CI}=0.056,2.158)$, while unemployment was a significant predictor of arousal disorder $(B=-0.634, \mathrm{CI}=-1.095,-0.173)$ and sexual pain disorder $(B=-0.691, \mathrm{CI}=-1.319,-0.063)$.

\section{Discussion}

This study examined the prevalence and correlates of sexual dysfunction among male and female patients with mental disorders attending the medical outpatient department of the University College Hospital, Ibadan. Overall, about $85 \%$ and $96 \%$ of male and female participants, respectively, had at least one form of sexual dysfunction. In the male patients, the most common forms were disorder of sexual desire, orgasmic dysfunction and sexual dissatisfaction. Unemployment, not being in a marital relationship and autonomic side effects of medications were the most important correlates of sexual dysfunction in the male participants. While for the female participants, important correlates included religion, unemployment, marital status, early age of onset of mental disorder and having a diagnosis of schizophrenia.

These prevalence rates for sexual dysfunction in this sample of patients with mental disorders are much higher compared to rates obtained in studies of the general population that ranged between $30 \%$ and $81 \%, 3,4,5,6,7,8$ Hence, this finding further supports previous studies that have similarly reported higher rates of sexual dysfunction among patients with mental disorders, with reported rates ranging between $40 \%$ and $96 \% .{ }^{9}, 10,11,12,13,14,15,16,17,18,19$ When disaggregated by gender, earlier studies have reported rates similar to that of this study $(75 \%-83 \%$ in male participants and $82 \%-96 \%$ in female participants). ${ }^{10,11,15,16,19}$ It is, however, pertinent to note that not all studies support the finding that patients with mental disorders have higher rates of sexual dysfunction compared to the general population.

Some studies have reported rates ranging between $40.4 \%$ and $68 \%$, which is within the range reported in studies of general adult population..$^{9,12,14,18}$ Factors that can account for the reported differences in rates include eligibility criteria for the selection of study participants and questionnaires used. In some of the studies that reported relatively lower rates, patients with comorbid psychoactive substance use disorder and comorbid medical conditions such as hypertension, diabetes, vascular diseases and other endocrine disorders were excluded..$^{9,12,14,18}$ It is well known that these conditions commonly coexist with mental disorders and are established 
TABLE 2: Socio-demographic and clinical correlates of sexual dysfunction among male participants.

\begin{tabular}{|c|c|c|c|c|c|c|c|c|c|c|c|c|}
\hline \multirow[t]{2}{*}{ Variable } & \multicolumn{2}{|c|}{$\begin{array}{l}\text { Erectile dysfunction } \\
\quad(106[73.6 \%])\end{array}$} & \multicolumn{2}{|c|}{$\begin{array}{c}\text { Orgasmic } \\
\text { dysfunction } \\
(113[78.5 \%])\end{array}$} & \multicolumn{2}{|c|}{$\begin{array}{c}\text { Sexual desire } \\
\text { disorder } \\
(125[86.8])\end{array}$} & \multicolumn{2}{|c|}{$\begin{array}{c}\text { Intercourse } \\
\text { dissatisfaction } \\
\text { (124 [86.1]) }\end{array}$} & \multicolumn{2}{|c|}{$\begin{array}{c}\text { Overall } \\
\text { dissatisfaction } \\
(110[86.1])\end{array}$} & \multicolumn{2}{|c|}{$\begin{array}{l}\text { Overall sexual } \\
\text { dysfunction } \\
\text { (122 [84.7]) }\end{array}$} \\
\hline & $X^{2}$ & $p$-value & $X^{2}$ & $p$-value & $X^{2}$ & $p$-value & $X^{2}$ & $p$-value & $X^{2}$ & $p$-value & $X^{2}$ & $p$-value \\
\hline \multicolumn{13}{|l|}{ Age (years) } \\
\hline $18-29$ & 0.899 & 0.826 & 1.742 & 0.628 & 1.642 & 0.650 & 1.709 & 0.635 & 3.124 & 0.373 & 3.327 & 0.344 \\
\hline $30-39$ & - & - & - & - & - & - & - & - & - & - & - & - \\
\hline $40-49$ & - & - & - & - & - & - & - & - & - & - & - & - \\
\hline $50-60$ & - & - & - & - & - & - & - & - & - & - & - & - \\
\hline \multicolumn{13}{|l|}{ Highest level of education } \\
\hline Primary & 0.550 & 0.759 & 2.469 & 0.291 & 1.125 & 0.570 & 2.761 & 0.251 & 4.486 & 0.096 & 1.424 & 0.491 \\
\hline Secondary & - & - & - & - & - & - & - & - & - & - & - & - \\
\hline Tertiary & - & - & - & - & - & - & - & - & - & - & - & - \\
\hline \multicolumn{13}{|l|}{ Marital status } \\
\hline Single & 3.083 & 0.214 & 6.250 & $0.044^{*}$ & 0.835 & 0.659 & 0.267 & 0.875 & 4.211 & 0.122 & 1.544 & 0.462 \\
\hline Married & - & & - & & - & & - & & - & & - & \\
\hline Divorced/separated/widowed & - & & - & & - & & - & & - & & - & \\
\hline \multicolumn{13}{|l|}{ Religion } \\
\hline Christian & 1.484 & 0.223 & 0.284 & 0.594 & 0.043 & 0.836 & 0.112 & 0.738 & 0.070 & 0.791 & 0.330 & 0.566 \\
\hline Islam & - & - & - & - & - & - & - & - & - & - & - & - \\
\hline \multicolumn{13}{|l|}{ Employment status } \\
\hline Skilled & 6.721 & $0.035^{*}$ & 2.491 & 0.288 & 12.733 & $0.002 *$ & 3.345 & 0.188 & 1.790 & 0.408 & 12.147 & $0.002 * *$ \\
\hline Unskilled & - & - & - & - & - & - & - & - & - & - & - & - \\
\hline Unemployed & - & - & - & - & - & - & - & - & - & - & - & - \\
\hline \multicolumn{13}{|l|}{ Age of onset of disease (years) } \\
\hline$\leq 18$ & 0.089 & 0.766 & 1.626 & 0.202 & 0.038 & 0.846 & 0.877 & 0.349 & 0.003 & 0.960 & 1.238 & 0.266 \\
\hline Above 18 & - & - & - & - & - & - & - & - & - & - & - & - \\
\hline \multicolumn{13}{|c|}{ Duration of illness before presentation (years) } \\
\hline$\leq 1$ & 0.134 & 0.935 & 0.511 & 0.924 & 2.181 & 0.336 & 3.291 & 0.193 & 0.802 & 0.670 & 0.453 & 0.797 \\
\hline $1-5$ & - & - & - & - & - & - & - & - & - & - & - & - \\
\hline$>5$ & - & - & - & - & - & - & - & - & - & - & - & - \\
\hline \multicolumn{13}{|l|}{ Number of previous episodes } \\
\hline 1 & 4.555 & 0.103 & 2.962 & 0.227 & 1.873 & 0.392 & 2.140 & 0.343 & 0.328 & 0.849 & 3.048 & 0.218 \\
\hline 2 & - & - & - & - & - & - & - & - & - & - & - & - \\
\hline$\geq 3$ & - & - & - & - & - & - & - & - & - & - & - & - \\
\hline Clinical diagnosis & & & & & & & & & & & & \\
\hline Depression & 2.520 & 0.472 & 3.295 & 0.348 & 4.080 & 0.253 & 4.987 & 0.173 & 6.017 & 0.111 & 1.319 & 0.725 \\
\hline Bipolar affective disorder & - & - & - & - & - & - & - & - & - & - & - & - \\
\hline Schizophrenia & - & - & - & - & - & - & - & - & - & - & - & - \\
\hline Others & - & - & - & - & - & - & - & - & - & - & - & - \\
\hline Presence of any comorbidity & & & & & & & & & & & & - \\
\hline Yes & 0.196 & 0.658 & 0.00 & 0.992 & 2.357 & 0.216 & 0.590 & 0.442 & 0.121 & 0.728 & 0.793 & 0.373 \\
\hline No & - & - & - & - & - & - & - & - & - & - & - & - \\
\hline Comorbidity substance use & & & & & & & & & & & & \\
\hline Yes & 0.694 & 0.405 & 1.847 & 0.174 & 0.918 & 0.338 & 0.737 & 0.391 & 1.260 & 0.262 & 0.012 & 0.914 \\
\hline No & - & - & - & - & - & - & - & - & - & - & - & - \\
\hline Duration of use of psychotrop & & & & & & & & & & & & \\
\hline$\leq 5$ years & 1.590 & 0.212 & 1.223 & 0.301 & 0.848 & 0.433 & 1.550 & 0.220 & 0.379 & 0.686 & 1.154 & 0.322 \\
\hline $6-10$ years & - & - & - & - & - & - & - & - & - & - & - & - \\
\hline$>10$ years & - & - & - & - & - & - & - & - & - & - & - & - \\
\hline Medication adherence & & & & & & & & & & & & \\
\hline Low & 0.408 & 0.666 & 1.579 & 0.212 & 1.267 & 0.287 & 3.374 & $0.039 *$ & 0.850 & 0.431 & 1.042 & 0.357 \\
\hline Medium & - & - & - & - & - & - & - & - & - & - & - & - \\
\hline High & - & - & - & - & - & - & - & - & - & - & - & - \\
\hline Depressive symptoms & & & & & & & & & & & & \\
\hline Absent & 0.001 & 0.984 & 0.378 & 0.540 & 0.126 & 0.723 & 0.080 & 0.778 & 2.305 & 0.132 & 0.375 & 0.542 \\
\hline Present & - & - & - & - & - & - & - & - & - & - & - & - \\
\hline
\end{tabular}

*, Statistically significant at $p<0.05$.

**, Remained statistically significant after logistic regression analysis.

risk factors of sexual dysfunction; hence, excluding such patients generates lower rates and makes the sample unrepresentative and findings of such studies are not generalisable to regular patients with mental disorders. ${ }^{2,31}$
In this study, male participants who are either unemployed or unskilled labourers had up to five times the risk of sexual dysfunction compared to those who were employed. Employment status in men is reported in the literature as an 
TABLE 3: Socio-demographic and clinical correlates of overall sexual dysfunction among female participants. Socio-demographic and clinical variables Overall sexual dysfunction

\begin{tabular}{|c|c|c|c|c|c|c|}
\hline \multirow{3}{*}{ variables } & \multirow{2}{*}{\multicolumn{2}{|c|}{ Yes }} & \multirow{2}{*}{\multicolumn{2}{|c|}{ No }} & \multirow{3}{*}{$X^{2}$} & \multirow{3}{*}{$p$} \\
\hline & & & & & & \\
\hline & $n$ & $\%$ & $n$ & $\%$ & & \\
\hline \multicolumn{7}{|l|}{ Age (years) } \\
\hline $18-29$ & 28 & 96.6 & 1 & 3.4 & 1.014 & 0.798 \\
\hline $30-39$ & 33 & 97.1 & 1 & 2.9 & - & - \\
\hline $40-49$ & 20 & 95.2 & 1 & 4.8 & - & - \\
\hline $50-60$ & 9 & 90.0 & 1 & 10.0 & - & - \\
\hline \multicolumn{7}{|l|}{ Highest level of education } \\
\hline Primary & 5 & 83.3 & 1 & 16.7 & 7.530 & $0.023 *$ \\
\hline Secondary & 26 & 89.7 & 3 & 10.3 & - & - \\
\hline Tertiary & 59 & 100.0 & 0 & 0.0 & - & - \\
\hline \multicolumn{7}{|l|}{ Marital status } \\
\hline Single & 33 & 100.0 & 0 & 0.0 & 3.676 & 0.159 \\
\hline Married & 46 & 92.0 & 4 & 8.0 & - & - \\
\hline Divorced/separated/widowed & 11 & 100.0 & 0 & 0.0 & - & - \\
\hline Christian & 70 & 98.6 & 1 & 1.4 & 5.772 & $0.016 *$ \\
\hline Islam & 20 & 87.0 & 3 & 13.0 & - & - \\
\hline \multicolumn{7}{|l|}{ Employment status } \\
\hline Skilled & 28 & 96.6 & 1 & 3.4 & 0.4107 & 0.814 \\
\hline Unskilled & 31 & 93.9 & 2 & 6.1 & - & - \\
\hline Unemployed & 31 & 96.9 & 1 & 3.1 & - & - \\
\hline \multicolumn{7}{|l|}{ Age at onset of disease (years) } \\
\hline$\leq 18$ & 25 & 100.0 & 0 & 0.0 & 1.514 & 0.219 \\
\hline Above 18 & 65 & 94.2 & 4 & 5.8 & - & - \\
\hline \multicolumn{7}{|c|}{ Duration of illness before presentation } \\
\hline$\leq 1$ year & 53 & 94.6 & 3 & 5.4 & 1.130 & 0.568 \\
\hline $1-5$ years & 17 & 94.4 & 1 & 5.6 & - & - \\
\hline Above 5 years & 20 & 100.0 & 0 & 0.0 & - & - \\
\hline \multicolumn{7}{|l|}{ Number of previous episodes } \\
\hline 1 & 10 & 90.9 & 1 & 9.1 & 1.616 & 0.446 \\
\hline \multicolumn{7}{|l|}{ Clinical diagnosis } \\
\hline Depression & 14 & 93.3 & 1 & 6.7 & 2.664 & 0.446 \\
\hline Bipolar affective disorder & 19 & 95.0 & 1 & 5.0 & - & - \\
\hline Schizophrenia & 51 & 98.1 & 1 & 1.9 & - & - \\
\hline Others & 6 & 85.7 & 1 & 14.3 & - & - \\
\hline \multicolumn{7}{|l|}{ Presence of any comorbidity } \\
\hline Yes & 6 & 85.7 & 1 & 14.3 & 1.868 & 0.172 \\
\hline No & 84 & 96.6 & 3 & 3.4 & - & - \\
\hline \multicolumn{7}{|l|}{ Comorbidity substance use } \\
\hline Yes & 2 & 100.0 & 0 & 0.0 & 0.090 & 0.763 \\
\hline No & 88 & 95.7 & 4 & 4.3 & - & - \\
\hline \multicolumn{7}{|c|}{ Duration of use of psychotropic medications } \\
\hline$\leq 5$ years & 57 & 98.3 & 1 & 1.7 & 3.312 & 0.191 \\
\hline $6-10$ years & 18 & 94.7 & 1 & 5.3 & - & - \\
\hline$>10$ years & 15 & 88.2 & 2 & 11.8 & - & - \\
\hline \multicolumn{7}{|l|}{ Medication adherence } \\
\hline Low & 40 & 95.2 & 2 & 4.8 & 1.786 & 0.409 \\
\hline Medium & 43 & 97.7 & 1 & 2.3 & - & - \\
\hline High & 7 & 87.5 & 1 & 12.5 & - & - \\
\hline Depressive symptoms $\dagger$ & & & & & & \\
\hline Absent & 52 & 94.5 & 3 & 5.5 & 0.435 & 0.509 \\
\hline Present & 37 & 97.4 & 1 & 2.6 & - & - \\
\hline
\end{tabular}

*, Statistically significant at $p<0.05$.

$\dagger, n<94$ among female participants because of missing data.

important determinant of overall sexual dysfunction, erectile dysfunction and sexual desire disorder. ${ }^{12,14}$

One of the social roles conferred on the male gender is the ability to provide for the basic needs of his partner and this role may be more challenging when the man is not employed. Failure to achieve this leads to role reversal within a relationship contrary to societal and cultural expectations, thereby engendering feelings of shame and inadequacy. ${ }^{12}$ Furthermore, unemployment in a person with 
TABLE 4: Socio-demographic and clinical correlates of the domains of sexual dysfunction among female participants.

\begin{tabular}{|c|c|c|c|c|c|c|c|c|c|c|c|c|}
\hline \multirow{2}{*}{$\begin{array}{l}\text { Socio-demographic and clinical } \\
\text { variables }\end{array}$} & \multicolumn{2}{|c|}{ Sexual desire disorder } & \multicolumn{2}{|c|}{ Arousal disorder } & \multicolumn{2}{|c|}{ Lubrication disorder } & \multicolumn{2}{|c|}{ Orgasmic dysfunction } & \multicolumn{2}{|c|}{ Sexual dissatisfaction } & \multicolumn{2}{|c|}{ Sexual pain disorder } \\
\hline & $t / f$-test & $p$-value & $t / f$-test & $p$-value & $t / f$-test & $p$-value & $t / f$-test & $p$-value & $t / f$-test & $p$-value & $t / f$-test & $p$-value \\
\hline \multicolumn{13}{|l|}{ Age (years) } \\
\hline $18-29$ & 1.486 & 0.224 & 1.980 & 0.123 & 1.603 & 0.194 & 2.089 & 0.107 & 1.084 & 0.360 & 3.865 & $0.012^{*}$ \\
\hline 30-39 & - & - & - & - & - & - & - & - & - & - & - & - \\
\hline $40-49$ & - & - & - & - & - & - & - & - & - & - & - & - \\
\hline $50-60$ & - & - & - & - & - & - & - & - & - & - & - & - \\
\hline \multicolumn{13}{|l|}{ Highest level of education } \\
\hline Primary & 1.078 & 0.345 & 2.328 & 0.103 & 3.941 & $0.023^{*}$ & 5.228 & $0.007^{*}$ & 0.715 & 0.492 & 2.754 & 0.069 \\
\hline Secondary & - & - & - & - & - & - & - & - & - & - & - & - \\
\hline Tertiary & - & - & - & - & - & - & - & - & - & - & - & - \\
\hline \multicolumn{13}{|l|}{ Marital status } \\
\hline Single & 1.180 & 0.312 & 10.325 & $0.001 *$ & 13.801 & $0.001 *$ & 12.155 & $0.001^{*}$ & 3.250 & 0.430 & 10.405 & $0.001^{*}$ \\
\hline Married & - & - & - & - & - & - & - & - & - & - & - & - \\
\hline Divorced/separated/widowed & - & - & - & - & - & - & - & - & - & - & - & - \\
\hline Christian & -1.133 & 0.260 & -2.430 & $0.017^{* *}$ & -2.167 & $0.033^{* *}$ & -2.103 & $0.038^{*}$ & -1.487 & 0.140 & -0.840 & 0.403 \\
\hline Islam & - & - & - & - & - & - & - & - & - & - & - & - \\
\hline \multicolumn{13}{|l|}{ Employment status } \\
\hline Skilled & 0.082 & 0.921 & 3.840 & $0.025 * *$ & 2.403 & 0.096 & 2.873 & 0.062 & 2.042 & 0.136 & 4.423 & $0.015^{* *}$ \\
\hline Unskilled & - & - & - & - & - & - & - & - & - & - & - & - \\
\hline Unemployed & - & - & - & - & - & - & - & - & - & - & - & - \\
\hline \multicolumn{13}{|l|}{ Age of onset of disease (years) } \\
\hline$<18$ & -2.235 & $0.028^{*}$ & -0.803 & 0.425 & -1.203 & 0.232 & -0.918 & 0.361 & 0.255 & 0.800 & -0.892 & 0.375 \\
\hline Above 18 & - & - & - & - & - & - & - & - & - & - & - & - \\
\hline \multicolumn{13}{|c|}{ Duration of illness before presentation } \\
\hline$<1$ year & 1.380 & 0.257 & 0.213 & 0.808 & 0.058 & 0.944 & 0.110 & 0.912 & 0.076 & 0.940 & 0.329 & 0.743 \\
\hline $1-5$ years & - & - & - & - & - & - & - & - & - & - & - & - \\
\hline Above 5 years & - & - & - & - & - & - & - & - & - & - & - & - \\
\hline 2 & - & - & - & - & - & - & - & - & - & - & - & - \\
\hline 3 or more & - & - & - & - & - & - & - & - & - & - & - & - \\
\hline Clinical diagnosis & & & & & & & & & & & & \\
\hline Depression & 0.070 & 0.976 & 2.967 & $0.036^{*}$ & 2.931 & $0.026^{*}$ & 1.970 & 0124 & 1.064 & 0.368 & 0.803 & 0.495 \\
\hline Bipolar affective disorder & - & - & - & - & - & - & - & - & - & - & - & - \\
\hline Schizophrenia & - & - & - & - & - & - & - & - & - & - & - & - \\
\hline Others & - & - & - & - & - & - & - & - & - & - & - & - \\
\hline Presence of any comorbidity & & & & & & & & & & & & \\
\hline Yes & 0.081 & 0.936 & 0.208 & 0.835 & 0.699 & 0.486 & 0.201 & 0.841 & 0.697 & 0.488 & 1.070 & 0.288 \\
\hline No & - & - & - & - & - & - & - & - & - & - & - & - \\
\hline Comorbidity substance use & & & & & & & & & & & & \\
\hline Yes & -1.872 & 0.065 & -0.899 & 0.371 & -0.481 & 0.632 & -0.457 & 0.649 & -0.883 & 0.380 & -1.860 & 0.853 \\
\hline No & - & & - & - & - & - & - & - & - & - & - & - \\
\hline Duration of use of psychotropic & edications & & & & & & & & & & & \\
\hline$\leq 5$ & 1.590 & 0.212 & 1.223 & 0.301 & 0.848 & 0.433 & 1.550 & 0.220 & 0.379 & 0.686 & 1.154 & 0.322 \\
\hline $6-10$ & - & - & - & - & - & - & - & - & - & - & - & - \\
\hline$>10$ & - & - & - & - & - & - & - & - & - & - & - & - \\
\hline Medication adherence & & & & & & & & & & & & \\
\hline Low & 0.408 & 0.666 & 1.579 & 0.212 & 1.267 & 0.287 & 3.374 & $0.039 *$ & 0.850 & 0.431 & 1.042 & 0.357 \\
\hline Medium & - & - & - & - & - & - & - & - & - & - & - & - \\
\hline High & - & - & - & - & - & - & - & - & - & - & - & - \\
\hline Depressive symptoms & & & & & & & & & & & & \\
\hline Absent & 0.001 & 0.984 & 0.378 & 0.540 & 0.126 & 0.723 & 0.080 & 0.778 & 2.305 & 0.132 & 0.375 & 0.542 \\
\hline Present & - & - & - & - & - & - & - & - & - & - & - & - \\
\hline
\end{tabular}

*, Statistically significant at $p<0.05$.

**, Remained statistically significant after logistic regression analysis.

a mental disorder has been associated with public and selfstigmatisation which may cause low self-esteem and poor sexual performance or satisfaction. ${ }^{32}$
Another correlate of sexual dysfunction reported in male participants in this study is the presence of autonomic side effects of psychotropic medications as indicated by the 
significantly higher mean scores on the UKU side effect rating. While we could not ascertain the reason for this relationship in male participants, difference in dosing of psychotropic medications between male participants and female participants is a possibility. However, this present report is based on self-reported measures and we did not verify medication dose; hence, we could not explore this association. An earlier study by Smith et al. ${ }^{18}$ similarly found that sexual dysfunction was associated with autonomic side effects of psychotropic medications in male patients. However, that study went further to show that this association was related to plasma prolactin levels; sexual dysfunction was associated with the presence of autonomic side effects of medication in those with normal plasma prolactin levels, but this association ceased to exist in those with elevated prolactin levels. Measurement of plasma prolactin levels was beyond the scope of this study, and therefore we cannot state whether plasma prolactin level had any relationship with this finding; however, it is worth noting that when we controlled for other associated factors, autonomic side effects remained a significant risk factor for sexual dysfunction. Autonomic side effects were only significantly related to male sexual dysfunction and not female in this study. Acetylcholine, a major neurotransmitter in the autonomic nervous system, plays a vital role in male sexual function causing the relaxation of smooth muscles of the corpus cavernosum that, in turn, leads to vasocongestion and penile erection. Hence, anticholinergic activities from the side effects of psychotropic medications could result in erectile dysfunction in male patients. It is interesting that medication adherence was not a correlate of sexual dysfunction in male participants but was associated with orgasmic dysfunction in female participants.

Marital status was significantly associated with sexual dysfunction in both male participants and female participants in this study. Male participants who were divorced, separated, widowed or single were more likely to experience arousal disorder, while female participants who were divorced, separated and widowed were more likely to experience arousal, lubrication, orgasmic and sexual pain disorders compared to those who were married. This is consistent with the findings of a study by Fanta et $a . .^{16}$ who reported that being unmarried, divorced or widowed was significantly associated with sexual dysfunction among female patients with mental disorders. The functional impairment from mental disorders as well as the low sexual desire which is more common among female patients might have negatively affected interpersonal and social skills necessary to initiate and maintain a marriage relationship, hence worsening the experience of desired sexual life. Educational status was significantly associated with the overall sexual dysfunction, lubrication and orgasmic disorders. A few studies among patients with mental disorders have reported an association between sexual dysfunction and educational status, ${ }^{33,34}$ consistent with the findings of this study.

Female sexual dysfunction was related to age, age at onset of mental illness, clinical diagnosis and medication adherence.
Although studies have found that sexual dysfunction including sexual pain disorder increases with age, this study found significantly lower mean scores for sexual pain disorder in female participants below the age of 30 years. While the specific reasons for this association in this population with mental disorders are unknown, young women in the general population have been reported to experience pain during sexual intercourse because of physical and psychosocial factors including congenital vulvovaginal abnormality, vulvovaginal infection, poorly repaired episiotomy after childbirth, pelvic trauma or surgery, sexual abuse and anxiety. ${ }^{35,36,37}$ Early age of onset of mental illness was found to be associated with disorder of sexual desire. The onset of mental illness in childhood and adolescence has been associated with greater illness severity, persistence of symptoms and lack of treatment response, which might affect the psychosexual development and adjustment essential for normal sexual functioning. ${ }^{38}$ Female patients with schizophrenia were found to be more likely to have sexual dysfunction in this study, which is similar to the findings of an earlier study among patients with schizophrenia in the United Kingdom. ${ }^{10}$

Religion and employment status emerged as the independent predictors of sexual dysfunction among female participants. Although religion has not been previously reported to be associated with sexual dysfunction in patients with mental disorders, religiosity has been reported to be a risk factor of sexual dysfunction in a community sample of women. ${ }^{39}$ It could be hypothesised that the association reported in this study may be because of the tendencies of some religious sects to consider the discussion of sexuality as a sacrilegious act, hence forbidding people, especially women, from talking about their sexual experiences and difficulties. ${ }^{40}$

The findings of this study should be interpreted bearing in mind the limitations. Firstly, this study employed a crosssectional study design that makes the inference of the direction of causality between sexual dysfunction and the socio-demographic and clinical variables difficult. Secondly, the study was conducted in a tertiary facility where the patients may not be a true representation of the demographics in primary and secondary healthcare facilities. This is because patients who are better educated or from higher socioeconomic classes may be over-represented in the population of patients receiving care in tertiary healthcare centres in Nigeria. Thirdly, the inclusion of patients with comorbid medical disorders as well as comorbid psychoactive substance use disorders could be a confounding factor as these disorders have been reported to also cause sexual dysfunction. There was also the possibility that some participants in this study had difficulty recalling events, such as age at onset of illness, duration of illness before presentation, duration of use of psychotropic medications, doses of medications and the number of previous episodes, which could have caused recall bias and affected the inference made. Furthermore, confounding factors that could have 
influenced the associations reported, such as the presence of comorbid medical disorders and hormonal levels, were not explored. Even though the instruments used in assessing sexual dysfunctions (the IIEF for male participants and the FSFI for female participants) have been assessed to have good psychometric properties in the Nigerian population, we cannot overlook the limitations of these instruments. These include their inability to measure distress and provide information about relevant aetiologic factors.

Despite these limitations, this study has contributed to expanding the knowledge base about the correlates of sexual dysfunction in male participants and female participants with serious mental disorders on treatment in Nigeria. The rates of sexual dysfunction were quite high among patients of both sexes with mental disorders. Although unemployment was a risk factor of sexual dysfunction in both male and female participants in this study, other factors were more specific to certain gender and type of sexual dysfunction. Medication adherence and depressive symptoms were not risk factors of sexual dysfunction among the participants, but autonomic side effect of psychotropic medications was a risk factor among male participants. While we did not explore the number of patients who were aware of this problem and the rates among those who had actually complained to their doctors, we know that this will be very low. There is an urgent need to increase the awareness about the high rates of sexual dysfunction in patients with mental disorders to encourage healthcare providers to routinely screen for them and provide appropriate interventions. More studies are required to further explore these associations with a view to determine the direction of causality and to explore the impact of sexual dysfunction on patient functioning and QoL.

Sexual dysfunction was highly prevalent among patients with mental disorders, particularly among female patients. Unemployment was a significant risk factor of sexual dysfunction in both sexes. In addition, while the presence of autonomic side effects of psychotropic medications predicted sexual dysfunction in male patients, practising Christianity as a religion predicted female sexual dysfunction.

\section{Acknowledgements}

The authors express their profound gratitude to all the staff members of the Department of Psychiatry, University College Hospital, Ibadan, and all the participants who voluntarily participated in this study. This study would not have been successful without their support, counselling and cooperation. The authors also appreciate $\mathrm{Mr}$ Martins Imhansoloeva for his valuable advice in data collection and analysis.

\section{Competing interests}

The authors declare that they have no financial or personal relationships that may have inappropriately influenced them in writing this article.

\section{Authors' contributions}

A.O.A. conceived the research idea that was planned with B.O. A.O.A. carried out the research and wrote the initial draft of the manuscript. A.O.A. and B.O. contributed to the final version of the manuscript. B.O. supervised the research.

\section{Funding information}

This research received no specific grant from any funding agency in the public, commercial or not-for-profit sectors.

\section{Data availability}

The data that support the findings of this study are available from the corresponding author, A.O.A., upon reasonable request.

\section{Disclaimer}

The views and opinions expressed in this article are those of the authors and do not necessarily reflect the official policy or position of any affiliated agency of the authors.

\section{References}

1. Stevenson RWD. Sexual medicine: Why psychiatrists must talk to their patients about sex. Can J Psychiatry. 2004;49(10):673-677. https://doi.org/10.1177/ 070674370404901004

2. Bos L, Fortini V, Cas I, et al. Sexual dysfunctions, psychiatric diseases and quality of life: A review. Psychiatr Pol. 2014;48(4):715-726.

3. Dunn KM, Croft PR, Hackett GI. Sexual problems: A study of the prevalence and need for health care in the general population. Fam Pract. 1998;15(6):519-524 https://doi.org/10.1093/fampra/15.6.519

4. Nwagha UI, Oguanuo TC, Ekwuazi K, Olubobokun TO, Nwagha TU, Onyebuchi AK. Prevalence of sexual dysfunction among females in a university community in
Enugu, Nigeria. Niger J Clin Pract. 2014;17(6):791-796. https://doi.org/10.4103/ Enugu, Nigeria. Niger

5. Shaeer KZM, Osegbe DN, Siddiqui SH, Razzaque A, Glasser DB, Jaguste V. Prevalence of erectile dysfunction and its correlates among men attending primary care clinics in three countries: Pakistan, Egypt, and Nigeria. Int J Impot primary care clinics in three countries: Pakistan, Egypt, and Nigeria.
Res. 2003;15 Suppl 1:S8-S14. https://doi.org/10.1038/sj.ijir.3900971

6. Fatusi AO, ljadunola KT, Ojofeitimi EO, et al. Assessment of andropause awareness and erectile dysfunction among married men in Ile-lfe, Nigeria. Ageing Male. 2003;6(2):79-85. https://doi.org/10.1080/tam.6.2.79.85

7. Nazareth I, Boynton P, King M. Problems with sexual function in people attending London general practitioners: A cross-sectional study. Br Med J. 2003; 327(7412):423. https://doi.org/10.1136/bmj.327.7412.423

8. Laumann EO. Sexual dysfunction in the United States. J Am Med Assoc 1999;282(13):1229. https://doi.org/10.1001/jama.282.13.1229-a

9. Hocaoglu C, Celik FH, Kandemir G, Guveli H, Bahceci B. Sexual dysfunction in outpatients with schizophrenia in Turkey: A cross-sectional study. Shanghai Arch Psychiatry. 2015;26(6):347-356.

10. MacDonald $S$, Halliday J, MacEwan $T$, et al. Nithsdale schizophrenia surveys 24 : Sexual dysfunction. Case-control study. Br J Psychiatry. 2003;182(Jan.):50-56. https://doi.org/10.1192/bjp.182.1.50

11. Oyekanmi A, Adelufosi A, Abayomi O, Adebowale T. Demographic and clinical correlates of sexual dysfunction among Nigerian male outpatients on conventional correlates of sexual dysfunction among Nigerian male outpatients on conventional 1756-0500-5-267

12. Kennedy $\mathrm{SH}$, Rizvi S. Sexual dysfunction, depression, and the impact of antidepressants. J Clin Psychopharmacol. 2009;29(2):157-164.

13. Olisah VO, Sheikh TL, Abah ER, Ajeigbe AFM. Sociodemographic and clinical correlates of sexual dysfunction among psychiatric outpatients receiving common psychotropic medications in a Neuropsychiatric Hospital in Northern Nigeria. Nige J Clin Pract. 2016;19(6):799-806. https://doi.org/10.4103/1119-3077.180063

14. Mosaku KS, Ukpong DI. Erectile dysfunction in a sample of patients attending a psychiatric outpatient department. Int J Impot Res. 2009;21(4):235-239. https:// doi.org/10.1038/ijir.2009.16

15. Fanta T, Haile K, Abebaw D, Assefa D, Hibdye G. Assessment of sexual dysfunction and associated factors among patients with schizophrenia in Ethiopia, 2017. BMC Psychiatry. 2018;18(1):1-9.

16. Letourneau EJ, Schewe PA, Frueh BC. Preliminary evaluation of sexual problems in combat veterans with PTSD. J Trauma Stress. 1997;10(1):125-132. https://doi. org/10.1002/jts.2490100112 
17. Smith SM, Keane VO, Ay RM. Sexual dysfunction in patients taking conventional antipsychotic medication. $\mathrm{Br} J$ Psychiatry. 2002;181(1):49-56. https://doi. org/10.1192/bjp.181.1.49

18. Harley EW-Y, Boardman J, Craig T. Sexual problems in schizophrenia: prevalence and characteristics. A cross-sectional survey. Soc Psychiatry Psychiatr Epidemiol. 2010;45(7):759-766

19. Hou CL, Zang Y, Rosen RC, et al. Sexual dysfunction and its impact on quality of life in Chinese patients with schizophrenia treated in primary care. Compr Psychiatry. 2016;65:116-121. https://doi.org/10.1016/j.comppsych.2015.11.002

20. Simiyon M, Chandra PS, Desai G. Sexual dysfunction among women with schizophrenia - A cross-sectional study from India. Asian J Psychiatry. 2016;24 93-98. https://doi.org/10.1016/j.ajp.2016.08.022

21. Esfehani RJ, Fazel N, Dashti S, Moshkani S, Hasanabad FH, Foji S. Female sexual dysfunction and its associated risk factors: An epidemiological study in the NorthEast of Iran. J Midwifery Reprod Heal. 2016;4(1):498-505.

22. Oyelade BO, Jemilohun AC, Aderibigbe SA. Prevalence of erectile dysfunction and possible risk factors among men of South-Western Nigeria: a populationbased study. Pan Afr Med J. 2016;24:124. https://doi.org/10.11604/pamj.2016. 24.124.8660

23. Serretti A, Chiesa A. Treatment-emergent sexual dysfunction related to antidepressants. J Clin Psychopharmacol. 2009;29(3):259-266. https://doi.org/ 10.1097/JCP.0b013e3181a5233

24. Wiegel M, Meston C, Rosen R. The Female Sexual Function Index (FSFI): Crossvalidation and development of clinical cutoff scores. J Sex Marital Ther. 2005; 31(1):1-20. https://doi.org/10.1080/00926230590475206

25. Ibrahim AW, Pindar SK, Yerima MM, et al. Medication-related factors of nonadherence among patients with schizophrenia and bipolar disorder: Outcome of a cross-sectional survey in Maiduguri, North-eastern Nigeria. J Neurosci Behav Heal. 2015;7(5):31-39. https://doi.org/10.5897/JNBH2015.0128

26. Fadare J, Olamoyegun M, Gbadegesin BA. Medication adherence and direct treatment cost among diabetes patients attending a tertiary healthcare facility in Ogbomosho, Nigeria. Malawi Med J. 2015;27(2):65-70. https://doi.org/10.4314/mmj.v27i2.7

27. Adewuya AO, Ola BA., Aloba OO. Prevalence of major depressive disorders and validation of the beck depression inventory among Nigerian adolescents. Eur Child Adolesc Psychiatry. 2007;16:287-292. https://doi.org/10.1007/s00787-006-0557-0
28. Awaritefe A. The Beck Depression Inventory in relation to some commonly used tests in Nigeria. Niger J Basic Appl Psychol. 1988;1:23-28.

29. James BO, Omoaregba JO, Eze G. Depression among patients with diabetes mellitus in a Nigerian teaching hospital. SAJP. 2010;16(2):61-64. https://doi. org/10.4102/sajpsychiatry.v16i2.232

30. Adewuya AO, Ologun YA. Factors associated with depressive symptoms in Nigerian adolescents. J Adolesc Health. 2006;39(1):105-110.

31. Lewis RW, Fugl-Meyer KS, Bosch R, et al. Epidemiology/risk factors of sexual dysfunction. J Sex Med. 2004(1):35-39. https://doi.org/10.1111/j.1743-6109. 2004.10106.x

32. Adewuya AO, Owoeye AO, Erinfolami AO, Ola BA. Correlates of self-stigma among outpatients with Mental Illness in Lagos, Nigeria. Int J Soc Psychiatry. 2011; 57(4):418-427. https://doi.org/10.1177/0020764010363522

33. Anil KBN, Shalini M, Sanjay RJ, Prasannakumar DR. Sexual dysfunction in women with alcohol dependence syndrome: A study from India. Asian J Psychiatr. 2017;28:9-14. https://doi.org/10.1016/j.ajp.2017.03.007

34. Diehl A, Da Silva RL, Laranjeira R. Female sexual dysfunction in patients with substance-related disorders. Clinics (Sao Paulo). 2013;68(2):205-212.

35. Meana M, Yitzchak B. Painful coitus: A review of female dyspareunia. J Nerv Ment Dis. 1994;182(5):264-272. https://doi.org/10.1097/00005053-199405000-00003

36. Graziottin A. Clinical approach to dyspareunia. J Sex Marital Ther. 2001;27(5): 489-501. https://doi.org/10.1080/713846803

37. Elmerstig E, Wijma B, Berterö C. Why do young women continue to have sexual intercourse despite pain? J Adolesc Heal. 2008;43(4):357-363. https://doi. org/10.1016/j.jadohealth.2008.02.011

38. Kessler RC, Amminger GP, Aguilar-Gaxiola S, Alonso J, Lee S, Ustün TB. Age of onset of mental disorders: a review of recent literature. Curr Opin Psychiatry 2007;20(4):359-364. https://doi.org/10.1097/YCO.0b013e32816ebc8c

39. Artiles Pérez V, Gutiérrez Sigler MD, Sanfélix Genovés J. Female sexual function and related factors. Aten Primaria. 2006;38(6):339-344. https://doi.org/10.1157/ 13093371

40. Peitl MV, Peitl V, Pavlovic E. Influence of religion on sexual self-perception and sexual satisfaction in patients suffering from schizophrenia and depression. Int Psychiatry Med. 2009;39(2):155-167. https://doi.org/10.2190/PM.39.2.d 